\title{
Workplace duties or opportunities? Challenge stressors, regulatory focus, and creativity
}

\author{
Claudia A. Sacramento ${ }^{\mathrm{a}, *}$, Doris Fay ${ }^{\mathrm{b}}$, Michael A. West $^{\mathrm{c}}$ \\ a Aston Business School, Work and Organisational Psychology, Birmingham B47ET, UK \\ ${ }^{\mathrm{b}}$ University of Potsdam, Department of Psychology, Work and Organizational Psychology, Karl-Liebknecht-Str. 24,14476 Potsdam, Germany \\ ${ }^{c}$ Lancaster University Management School, Lancaster LA1 4YX, UK
}

\section{A R T I C L E I N F O}

\section{Article history:}

Received 7 April 2010

Accepted 25 January 2013

Available online 6 March 2013

Accepted by Linn Van Dyne

\section{Keywords:}

Creativity

Regulatory focus

Challenge stressors

Teams

\begin{abstract}
A B S T R A C T
Previous research has produced contradictory findings about the impact of challenge stressors on individual and team creativity. Based on the challenge-hindrance stressors framework (LePine, Podsakoff, \& LePine, 2005) and on regulatory focus theory (Higgins, 1997), we argue that the effect of challenge stressors on creativity is moderated by regulatory focus. We hypothesize that while promotion focus strengthens a positive relationship between challenge stressors and creativity, prevention focus reinforces a negative relationship. Experimental data showed that high demands led to better results in a creative insight task for individuals with a strong trait promotion focus, and that high demands combined with an induced promotion focus led to better results across both creative generation and insight tasks. These results were replicated in a field R\&D sample. Furthermore, we found that team promotion focus moderated the effect of challenge stressors on team creativity. The results offer both theoretical insights and suggest practical implications.
\end{abstract}

(c) 2013 Elsevier Inc. All rights reserved.

\section{Introduction}

With an uncertain economic environment and increasing worldwide competition, many organizations perceive employee creativity as key to innovation and financial performance (Amabile, 1988; Woodman, Sawyer, \& Griffin, 1993). Organizations have hence focused on maximizing employee creativity, defined as the generation of new and useful ideas (Amabile, 1988, 1996), as a strategy for survival and success. However, the same economic forces that demand creativity also translate into increasing levels of work stressors such as high job demands. It is therefore important to understand how such stressors can affect employees' responses to these organizational expectations and to answer the question when do demands impair creativity and when do they lead to creativity. Advancing our understanding of these issues is fundamentally important if we are to develop people management strategies that enable employees to respond creatively to demands, rather than being overwhelmed by them.

Research examining the impact of stressors on creativity has found contradictory results, with theoretical approaches and empirical findings suggesting positive, negative, and curvilinear effects (see Byron, Khazanchi, \& Nazarian, 2010, for an overview). The challenge-hindrance stressors framework argues that the nat-

\footnotetext{
* Corresponding author. Address: Work and Organisational Psychology, 8th Floor SW, Aston Business School, Aston University, Birmingham B4 7ET, UK.

E-mail address: c.a.sacramento@aston.ac.uk (C.A. Sacramento).
}

ure of the stressor is critical for understanding its effects (LePine, Podsakoff, \& LePine, 2005). This perspective therefore holds considerable promise for clarifying the relationship between stressors and creativity. Indeed, hindrance stressors (such as job insecurity and organizational politics) have been consistently shown to impair creativity (Aryee, Zhou, Sun, \& Lo, 2009; Probst, Stewart, Gruys, \& Tierney, 2007; Zhou, 2003). However, in relation to challenge stressors (such as job demands and high responsibility), the research findings are inconsistent (e.g. Amabile et al., 2002; Janssen, 2000; Ohly \& Fritz, 2010). This lack of clarity hinders theory development and means we cannot advise practitioners about how best to promote creativity amongst employees. Our lack of understanding is all the more concerning because challenge stressors such as job demands and pressure to perform well are arguably the kinds of stressors that employees experience most frequently, often on a daily basis (e.g., Bowers, 2007; Wall et al., 1997).

In order to shed light on these inconsistent findings we depart from the assumption implied in the challenge-hindrance framework that challenge stressors have a generalized positive effect on creativity (Lepine et al., 2005). In this paper we extend existing research on the stressor-creativity link by taking individuals' selfregulatory approach into account. We suggest that peoples' responses to challenge stressors will depend on how they view their working environments and whether this view conceptualizes challenge stressors as an opportunity for achievement of ideals and gains or as situations that require the avoidance of losses and fulfilment of oughts and duties. If they see the latter, then they are un- 
likely to be creative in their responses. If they see challenge stressors as an opportunity, their response is more likely to be creative. We base our reasoning on regulatory focus theory (Higgins, 1997), which offers a promising perspective on the study of this relationship and may help to explain the conflicting findings described above. The two motivational foci outlined by the theory, promotion and prevention focus, have pervasive impacts on the nature of goals pursued, on the way people process information and on their behavioral approaches during goal pursuit (Higgins, 1997). We suggest that those differences can account for both positive (promotion) and negative (prevention) effects of challenge stressors. While elevated levels of challenge stressors create a requirement to act, promotion and prevention foci will determine the extent to which the response will be more or less creative.

Thus, the key contribution of the present research is to address previous inconsistent theoretical predictions and empirical findings regarding the effect of stressors on creativity by integrating self-regulation theories into the challenge-hindrance stressors framework. We offer an analysis that helps explain how challenge stressors can, in the right circumstance, produce higher levels of individual and team creativity in the workplace.

\section{Theoretical background}

\section{Stressors and creativity}

Stressors are defined as environmental events in the workplace requiring an adaptive response of some kind (Kahn \& Byosiere, 1992; Sonnentag \& Frese, 2002). Although stressors are typically regarded as having a generalized negative impact (Gilboa, Shirom, Fried, \& Cooper, 2008; Kahn \& Byosiere, 1992), empirical results have shown that they can also be associated with positive outcomes such as personal initiative (Fay \& Sonnentag, 2002). A recent framework has suggested that the impact of stressors can best be understood by distinguishing between challenge stressors, which are those that people tend to appraise as potentially promoting their personal growth and achievement (e.g., workload, time pressure, job scope and high responsibility), and hindrance stressors, which are those that people tend to appraise as potentially constraining their personal development and work-related accomplishments (e.g., organizational politics, red tape, role ambiguity, job insecurity; Cavanaugh, Boswell, Roehling, \& Boudreau, 2000; LePine, LePine, \& Jackson, 2004). Meta-analytic evidence has supported this position, showing that challenge stressors have positive relationships with job satisfaction, organizational commitment and job performance, and negative relationships with turnover intentions, turnover, and withdrawal behavior, whereas hindrance stressors are inversely related to the same outcomes (LePine et al., 2005; Podsakoff, LePine, \& LePine, 2007).

The negative effects of hindrance stressors are generally accounted for by the mediating role of experienced strain (LePine et al., 2005). The explanation of the effects of challenge stressors, however, is more complex. Drawing on expectancy theory, LePine et al. (2005) argued that challenge stressors lead to motivation because people are more likely to perceive a positive relationship between effort expended in coping with these demands and the likelihood of overcoming them and consequently achieving valued outcomes. The opposite is the case for hindrance stressors. Thus, although challenge stressors lead to strain, they also trigger offsetting effects via motivation gains that override the depletion caused by strain (LePine et al., 2005). However, recent meta-analytic results still show very large credibility intervals for the effects of challenge stressors, such as role overload, on general performance (-.38 to .22) (Gilboa et al., 2008). This suggests that a substantial amount of the variance remains unexplained.
This complexity is also reflected in the theoretical literature on creativity, which is characterized by contradictory predictions about the effect of stressors in general on creativity (Byron et al., 2010). In cognitive resources theory, stressors are expected to impair creativity, as they tax too highly the limited cognitive resources necessary for creativity (Vecchio, 1990). In contrast arousal based theories suggest a positive relationship, in that stressors create both a demand for creativity and the motivational arousal to respond. Activation theory offers a further prediction by suggesting a curvilinear relationship: the activation caused by stressors leads to task engagement, which can facilitate creativity, but beyond a certain point this activation can cause cognitive interference, impairing creativity (Gardner, 1986). The challenge-hindrance framework offers - to some extent - a way of reconciling these contradictory positions by taking the nature of the stressor into account.

Although this framework has not been directly applied to the study of creativity, prior studies have shown that hindrance stressors fairly consistently impaired creativity (e.g., organizational politics and job insecurity; Aryee et al., 2009; Probst et al., 2007; Zhou, 2003). However, the results relating to challenge stressors are inconsistent. For example, a number of studies have reported a positive relationship between the challenge stressor of time pressure and creativity (e.g. Andrews \& Farris, 1972; Ohly \& Fritz, 2010), while others have found a negative effect of time pressure on creative cognitive processing (Amabile et al., 2002). Other studies found no significant relationship between the two constructs (De Dreu \& West, 2001), or that this relationship was dependent on third factors such as perceptions of fairness rewards (Janssen, 2000). We propose that these conflicting findings can be resolved by taking regulatory focus theory into account.

\section{Regulatory focus}

Regulatory focus theory proposes the existence of two distinct motivational orientations: motivation with a promotion focus, orientated towards ideals and achieving gains, and motivation with a prevention focus, focused on ensuring security and avoiding losses (Higgins, 1997). Individuals possess both self-regulatory foci, but there are stable individual differences in the relative propensity to adopt one or the other. Despite this stability, situational factors can temporarily induce a focus on promotion or prevention, and lead individuals to display a momentary (state) regulatory focus (Higgins, 1997). Each focus is associated with different goals and desired end-states, different processing styles and cognitive strategies used to attain the desired end-states, and different behavioral approaches (Higgins, 1997).

While previous work has focused on the main effect of regulatory focus on creativity, with research findings supporting overall a positive effect of promotion focus (e.g., Friedman \& Förster, 2000; Friedman \& Förster, 2001, 2002; Lam \& Chiu, 2002), we move away from this main effects approach to focus instead on the role of regulatory focus as a boundary condition of the effects of challenge stressors on creativity. We argue that the encompassing nature of regulatory focus holds the key to explaining previous inconsistent findings on the relationship between challenge stressors and creativity.

\section{The effect of challenge stressors and regulatory focus on creativity}

Challenge stressors are work events that require an adaptive response (LePine et al., 2004). Whether the adaptive response will be an act of applying something tried-and-tested or developing something creative will depend on whether individuals are more strongly promotion or prevention oriented. 
Promotion and prevention focus are associated with different desired end-states (goals) and different strategies to achieve them (Higgins, 1997). Research has shown that people with a strong promotion focus are sensitive to the presence and absence of positive outcomes; are vigilant for opportunities; and employ approaching, eager strategies towards their goals. In contrast, people with a strong prevention focus emphasize safety and the avoidance of losses; are sensitive to the presence and absence of negative outcomes; are attentive to the possibility of threat; and employ avoidant, vigilant strategies (Crowe \& Higgins, 1997; Higgins, 1997).

We argue that in promotion oriented individuals, a challenge stressor's pressure for an adaptive response activates the promotion strategies, i.e., eager strategies. This eager approach is characterized by a stronger preference to engage in errors of commission rather than omission and a desire not to miss any opportunities (Crowe \& Higgins, 1997; Liberman, Molden, Idson, \& Higgins, 2001). This, in turn, will result in the display of more divergent solutions in response to situational demands. In contrast, in individuals with a strong prevention orientation, due to their receptivity to unfavourable cues, the challenge stressor's pressure to act reinforces the use of prevention strategies, i.e., the adoption of a more avoidant, vigilant approach (Crowe \& Higgins, 1997; Liberman et al., 2001). Such individuals will resort to well-known and tested approaches, resulting in more conservative and less creative responses.

In addition, we suggest that regulatory focus also influences cognitive processes in the face of challenge stressors by affecting the range of cognitive elements available. In essence, the creative process involves making new associations between cognitive elements, resulting in ideas that can be selected to address a given problem (Mednick, 1962). However, only cognitive elements that are activated during the creative process can be used to produce new answers. Thus, the wider the range of available cognitive elements, the greater the possibility that unusual associations will occur and the larger will be the range of available ideas to respond to challenge stressors (Mednick, 1962).

Empirical research has shown that promotion focus is associated with a more holistic, global processing style, relying more on heuristics, while prevention focus is associated with analytic thinking, accuracy, and a more focused and localized processing style (e.g. Friedman \& Förster, 2000, 2001; Semin, Higgins, de Montes, Estourget, \& Valencia, 2005). An elevated level of challenge stressors demands an adaptive response. For individuals with a prevention focus, this will activate the associated cautious processing style; this in turn enhances attentional perseverance on initially retrieved cognitive elements, thereby inhibiting the retrieval of additional and more novel exemplars. In contrast, for individuals with a promotion orientation, an elevated level of challenge stressors activates the associated more open processing style; this facilitates the retrieval of novel responses by mitigating retrieval blocking, resulting in the activation of more (and more divergent) exemplars (Friedman \& Förster, 2000, 2001). Thus, a prevention focus, which represents a more conservative, perseverant, risk-averse processing style, reduces the material available for the generation of creative insights that would, in combination with challenge stressors, result in more creative solutions. In contrast, the more holistic processing style associated with promotion focus allows for a larger number of connections between a larger set of cognitive elements, enabling a wider range of possible responses to challenge stressors, thus enhancing creativity.

Finally, above and beyond affecting cognitive processes, regulatory focus also influences individuals' decisions and behaviors; this happens in ways that are likely to produce differential responses to challenge stressors. People with a strong promotion focus tend to engage in more risky behaviors than those with a strong prevention focus (Hamstra, Bolderdijk, \& Veldstra, 2011; Werth \& Förster,
2007), and risk taking is associated with creativity (Dewett, 2007). Challenge stressors require adaptation to a situation, and it might be necessary to decide whether or not to try a new solution to overcome the present demands. Faced with this situation, we argue that promotion focused people will be more likely to select a riskier and untested solution, and thereby often a more creative one. In contrast, prevention focused people will prefer to resort to tried and tested actions in order to cope with adversity, and thus choose safer, more conservative, and thereby less creative responses.

Thus, not only do promotion focused individuals have a wider range of solutions available when facing challenge stressors, they are also more likely to select solutions that are risky and creative; in contrast, prevention focused individuals not only have a narrower, less creative set of solutions available, they also tend to pursue the safer, less creative options. Based on the reasoning above, we formalize the following hypotheses:

Regulatory focus moderates the impact of challenge stressors on creativity in such a way that the relationship becomes positive as promotion focus strength increases (hypothesis 1a); and becomes negative as prevention focus strength increases (hypothesis 1b).

We focus on a specific challenge stressor, job demands, which is conceptualized as a multifaceted construct relating to requirements to work fast and hard, having high time pressure and being exposed to high performance expectations (Janssen, 2000, 2001; Karasek, 1979). We selected this challenge stressor for two reasons. First, job demands as a concept is probably one of the most pervasive stressors in work settings. Second, due to its multifaceted character this construct offers a relatively comprehensive representation of challenge stressors as conceptualized by the challenge-hindrance stressor framework.

We test our hypotheses by examining how the interplay between job demands and regulatory focus affects different aspects of creativity, in both experimental (study 1 ) and field (study 2 ) settings. In study 1 we test the moderator role of trait regulatory focus on the effects of induced demands on creative insight (part 1); and the interactive effects of induced state regulatory focus and demands on both creative insight and creative generation (part 2). In study 2 we aim to replicate the effects in a field study by examining how the interplay between the two variables affects creativity in a sample of R\&D professionals, at both the individual and team level.

\section{Method}

\section{Overview study 1}

In study 1 we conducted two consecutive experiments to examine the moderating effects of trait (part 1) and state (part 2) regulatory focus on the relationship between an induced challenge stressor, work demands, ${ }^{1}$ and creativity.

\section{Sample and procedure}

Eighty participants were randomly selected from a wider pool of 150 UK students who volunteered after a call offering a $£ 10$ voucher for participation in a psychology study was issued in the students' newsletter. Five participants failed to attend the session on the scheduled day and two participants were excluded from the analyses in part 2 of the study as the manipulation check indicated that the manipulation had not worked in their particular cases,

\footnotetext{
${ }^{1}$ Note that we use the term work demands instead of job demands in relation to the experimental study due to the absence of a job context.
} 
leaving a total sample size of 75 (73 in part 2). Average age was 20.5 years $(S D=2.75), 58$ participants were female $(79.5 \%)$.

One week prior to the scheduled session, participants received a link to an online survey that included a consent form, demographic questions and the chronic regulatory focus measure. The experiment was carried out in individual sessions which were conducted by three research assistants, naïve to the hypotheses. Upon arrival, participants were told that the study examined different cognitive styles and they would be asked to solve a number of cognitive tasks, which were in reality the creativity tasks. All instructions, manipulations and tasks were included in a booklet that was provided to the participants, and were also read aloud by the research assistant. Participants were randomly allocated to one of four conditions, Work Demands [high vs. low; relevant for part 1 and part 2 of the experiment] $\times$ State Regulatory Focus [promotion vs. prevention; relevant for part 2].

In part 1 of the experiment participants were exposed only to the work demands manipulation and were asked to work on the first creativity task, the Gestalt Completion Task (GCT). After this, they completed a post-task questionnaire including a work demands manipulation check. This concluded part 1 . In part 2 we proceeded by introducing the regulatory focus manipulation and repeated the work demands manipulation. Participants then worked on two different creativity tasks, the Snowy Pictures Test (SPT) and the Unusual Uses Test (UUT). Finally, they answered a second post-task questionnaire including manipulation checks and measures of potential mediating variables. The duration of the entire experiment was approximately $40 \mathrm{~min}$. Detailed procedures and results are described next.

\section{Study 1, part 1}

The aim of part 1 was to examine the extent to which trait regulatory focus moderates the influence of induced work demands on creativity.

\section{Measures and manipulations.}

Manipulation of work demands. Participants were randomly allocated to a high $(n=36)$ or low $(n=39)$ work demands condition. We aimed to model different aspects of job demands as they are experienced in real work settings, thus the manipulation included references to task difficulty, relevance of the task, accountability, and pressure to perform well. In addition, although there was no reference to time limit, participants in the high demands condition heard a stopwatch sound signalling the start and ending of each task, while in the low demands condition the stopwatch was silent and participants only listened to the research assistant's instructions. The specific wording is reproduced below.

High demands: "You will be asked to solve a number of cognitive tasks. These tasks are demanding and our previous research involving other students has shown that performance in these types of tasks is very highly correlated with future academic and job performance. Over the next 2 weeks, your answers will be critically analyzed and evaluated by the Principal Investigator of this project, and by a panel of researchers in the area of cognitive skills. You will afterwards be contacted by a member of the research team to explain some of your answers. For the continuation of the funding for this project, the results obtained by participants are critical, so it is really crucial that you work hard and perform these tasks very well."

Low demands: "You will be asked to solve a number of cognitive tasks. Please try to do your best".

Trait regulatory focus. We used the 11-item Regulatory Focus Questionnaire (RFQ; Higgins et al., 2001) to assess trait regulatory focus. An example of a promotion focus item is "Do you often do well at things that you try?"; $\alpha=.71$. An example of a prevention
Table 1

Study 1 part 1 . Interaction of trait regulatory focus and work demands on Gestalt Completion Task.

\begin{tabular}{lcccc}
\hline Variable & $R^{2}$ & Adj. $R^{2}$ & $\Delta R^{2}$ & \multicolumn{1}{c}{$\beta$} \\
\hline Step 1 & .03 & -.01 & .03 & \\
Trait promotion focus & & & & .12 \\
Trait prevention focus & & & & .11 \\
Work demands (low = 0; high = 1) & & & & -.02 \\
Step 2 & .11 & .05 & .08 & \\
Trait promotion focus & & & & -.15 \\
Trait prevention focus & & & & .15 \\
Work demands & & & -.02 \\
Trait promotion focus $\times$ work demands & & & -.07 \\
Trait prevention focus $\times$ work demands & & & \\
\hline
\end{tabular}

$p<.05$, two-tailed.

focus item is "How often did you obey rules and regulations that were established by your parents?"; $\alpha=.82$. Participants responded on a scale from 1 = "never or seldom"|"certainly false" to 5 = "very often"|"certainly true".

Creativity. Consistent with previous experimental studies (Friedman \& Förster, 2000, 2001) we used measures of creative insight. Insight is a transitory event in which one moves from a state of not knowing how to solve a problem to a state of knowing how to do it (Schooler \& Melcher, 1995). We selected the Gestalt Completion Task (GCT), which captures the ability to restructure ambiguous stimuli. It requires shifting perspective and recoding fragmented images in order to recognize familiar objects (Ekstrom, French, \& Harman, 1976). Participants were given 3 min to work on 10 incomplete objects they had to identify. GCT scores were computed by summing the number of fragmented objects correctly identified.

Analysis and results. To assess the efficacy of the manipulation we developed a nine item measure of work demands mirroring Janssen's (2000) job demands scale. Examples are "I found this task difficult", and "I was under pressure to work well"; $\alpha=.91$. Participants in the high work demands condition experienced higher demands $(M=5.29, S D=.98)$ than participants in the low demands condition $(M=4.47, S D=1.20), t(71)=-3.32, p=.002$.

In order to test our hypotheses we regressed trait regulatory focus and the experimental factor work demands (low = 0; high =1) on GCT. We used standardized values for regulatory focus when creating the interaction terms. $^{2}$

As expected, we found a significant effect for the moderator role of promotion focus $(b=.40, p=.014$; cf. Table 1$)$. As depicted in Fig. 1, the relationship between work demands and creativity is stronger as promotion focus increases. Analyses of the simple slopes for high and low promotion focus showed that the relationship between work demands and creativity was positive when promotion focus was high $(b=.42, p=.013)$, while the simple slope was not significant when promotion focus was low $(b=-.15, n s)$. The results were however not significant for the interaction between prevention focus and work demands $(b=-.07, n s)$. We did not find a main effect of either work demands or regulatory focus on creativity.

Discussion. The first part of this study showed that trait promotion focus moderates the influence of work demands on a creative insight test; under high work demands participants with a stronger promotion focus were more creative than participants with a weaker promotion focus. However, we did not find the same effect

\footnotetext{
${ }^{2}$ In all analyses we tested an alternative statistical model controlling for research assistant and the pattern of results remained unaltered.
} 


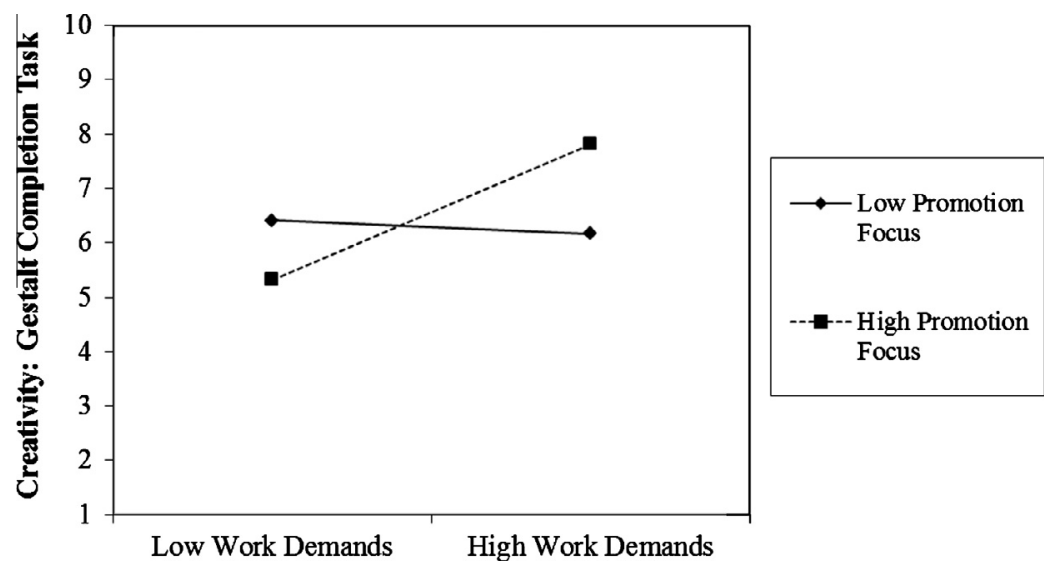

Fig. 1. Study 1 part 1. Interaction effect of work demands and trait promotion focus on the Gestalt Completion Task.

for prevention focus, lending only partial support to our hypotheses.

\section{Study 1, part 2}

The purpose of the second part of the study was to contrast the effect of an induced promotion focus with an induced prevention focus on the relationship between work demands and creativity. We also wanted to rule out alternative explanations that could account for the moderation effect of regulatory focus. In particular, there is a great deal of evidence showing the influence of affect and motivation on creativity (Amabile, 1996; Isen, Daubman, \& Nowicki, 1987). In addition, the challenge-hindrance-stressors framework also identifies motivation and strain as processes via which challenge stressors affect work related outcomes (LePine et al., 2005). It is possible that the manipulation of regulatory focus differentially affected emotional states, intrinsic motivation or experienced strain, thereby engendering enhanced creativity by way of other mechanisms than regulatory focus. To address these mediational issues and to determine whether the interactive effect of regulatory focus is independent of affect, intrinsic motivation and strain, we included measures of these variables. Finally, we also analyzed the extent to which this result was replicated across different aspects of creativity by including a creative generation task (Torrance, 1974) in addition to an insight task. The hypotheses were tested with a $2 \times 2$ (Work demands [high, low] $\times$ State regulatory focus [promotion, prevention]) between-subjects factorial design.

Procedure. After the conclusion of the first part of the study, we informed participants that before they continued solving the tasks we wanted them to participate in an unrelated study examining how peoples' views change over time. This was the first manipulation of regulatory focus. They were then asked to answer a question concerning how they were going to use their voucher, which was the second manipulation of regulatory focus. We then repeated the manipulation of work demands. Note that we chose to maintain participants in the same work demands condition instead of randomly assigning them again to high or low demands as presenting them with a second scenario contradicting the first would have probably raised doubts concerning the veracity of the cover story. In addition, we would also be introducing a new undesired variable, whether participants had been allocated to the same or to different demands conditions across both parts of the experiment. Participants were next asked to complete a word identification task, which was in reality the third manipulation of regulatory focus. Participants then worked on the two creativity tasks (Snowy Pictures Test and Unusual Uses Test), followed by a second post-task survey. Upon completion participants were debriefed, asked not to discuss the experiment with others, thanked, and given a $£ 10$ voucher for their participation.

\section{Manipulations and measures.}

Manipulation of regulatory focus. Momentary regulatory focus was induced with three procedures. First, participants were asked to write an essay on how their hopes and aspirations (promotion) or duties and obligations (prevention) had changed since they were a child to now (Higgins, Roney, Crowe, \& Hymes, 1994; Liberman, Idson, Camacho, \& Higgins, 1999). Next, we adapted a manipulation related to current ideals/oughts (Freitas, Liberman, Salovey, \& Higgins, 2002) and asked participants to write short essays about what they ideally would like to buy with the voucher (promotion focus) or what they thought they should buy with the voucher in order to use it responsibly (prevention focus). Finally, participants were asked to identify for each of three sets of three words the word that was unrelated with the other two. Except for three unrelated neutral words which were kept the same in both conditions, in the promotion condition all words were associated with ideals and success while in the prevention condition all words were associated with oughts and duties.

Manipulation of work demands. We manipulated work demands by using the same instructions as in part 1 , just preceded by the sentence "We should remind you that ...".

Creativity. The first creativity task was the Snowy Pictures Test (SPT), which is a measure of creative insight that requires breaking a context-induced mental set (Ekstrom et al., 1976). The SPT requires dis-embedding images of familiar objects from intricate patterns of visual noise. Participants were given 3 min to work on 12 pictures. SPT scores were computed by summing the number of embedded images correctly identified.

The second task was an Unusual Uses Test (UUT), which captures idea generation (Torrance, 1974). Creative generation tasks, in contrast with creative insight, do not have a specific solution, nor do they typically involve an impasse to be overcome, but require individuals to generate as many ideas as possible concerning a problem (Friedman \& Förster, 2002). In this case, the task consisted of generating as many original and useful uses as possible for a paper clip. Participants were stopped after $90 \mathrm{~s}$. UUT scores were computed by summing the number of answers provided.

In the post-task survey we measured strain with three items adapted from Caplan, Cobb, French, Van Harrison, and Pinneau (1975) anxiety measure, e.g., "I felt anxious while doing these tasks"; $\alpha=.88$. Intrinsic motivation was measured with three items, e.g., "I found these tasks engaging"; $\alpha=.85$ (Amabile et al., 2002). Positive and negative affect were measured with four items 
each (Friedman \& Förster, 2001), examples are respectively "happy" $(\alpha=.87)$; and "worried" $(\alpha=.85)$. All items were measured in a $1=$ completely disagree to $7=$ completely agree, Likert scale.

\section{Analysis and results.}

Manipulation checks. We used the same scale as in part 1 to capture perceived work demands $(\alpha=.92)$. Participants in the high work demands condition scored higher $(M=5.61, S D=.81)$ than participants in the low demands condition $(M=4.68, S D=1.30)$, $t(71)=-3.62, p=.001$. To check our manipulation of regulatory focus we asked participants to recall the two questions they had answered in relation to changes in perception over lifetime and uses for the voucher. Two participants failed to recall this and were excluded from the analysis. In addition, we randomly selected 10 short essays from each condition to verify whether participants had followed the manipulations' instructions (Leonardelli, Lakin, \& Arkin, 2007). Our analysis of the essays' content showed that participants in the promotion focus condition did indeed write about their ideals and aspirations and provided examples of nonessential but desirable items when asked about how the voucher could be spent; those in the prevention focus condition wrote about duties and obligations and did, as expected, provide examples of essential items.

Test of hypotheses. We tested our hypothesis in a MANOVA in which the two measures of creativity were entered as dependent variables. As shown in Table 2, a significant multivariate interaction effect emerged $\left(F(2,68)=5.95, p=.004\right.$, partial $\left.\eta^{2}=.15\right)$, supporting our interaction hypothesis. Univariate tests also showed that this effect was significant for both the SPT $(F(1,69)=5.78$, $p=.019$, partial $\left.\eta^{2}=.08\right)$ and the UUT $(F(1,69)=7.46, p=.008$, partial $\eta^{2}=.10$ ). Table 3 presents the means for the creativity tasks for each experimental group. Across tasks, the highest creativity scores always emerged in the high work demands - promotion focus condition while the lowest scores occurred in the high work demands - prevention focus condition. This is also depicted in Figs. 2 and 3.

We also found a marginally significant multivariate effect for regulatory focus $\left(F(2,68)=2.40, p=.099\right.$, partial $\eta^{2}=.07$; Table 2$)$. Participants induced with a promotion focus obtained better results in both the Snowy Pictures Test $\left(M_{\text {promotion }}=4.30, S E=.34 ; M_{\text {preven- }}\right.$ tion $=3.47, S E=.35, p=.095)$ and in the Unusual Uses Test $\left(M_{\text {promo- }}\right.$ tion $\left.=5.31, S E=.33 ; M_{\text {prevention }}=4.57, S E=.34, p=.120\right)$. We did not find a significant effect for work demands $(F(2,68)=.63, n s)$.

A supplementary analysis was conducted to address whether the moderating effect of regulatory focus was independent of the effects of affect, intrinsic motivation and strain. First, a series of MANOVAs entering the two creativity tasks as dependent variables were performed, separately including post-task measures of positive and negative affect, intrinsic motivation and strain as auxiliary predictors. These analyses only revealed the interaction effect of regulatory focus and work demands. A final series of ANOVAs using the four post-task measures as dependent variables and regulatory focus and work demands as interactive predictors revealed only a main negative effect of work demands on positive affect

Table 2

Study 1 part 2 . Multivariate analysis of variance.

\begin{tabular}{llcl}
\hline Source & $d f$ & $F$ & $p$ \\
\hline Regulatory focus (RF) & 68 & $2.40^{\dagger}$ & .099 \\
Work demands (WD) & 68 & .63 & .535 \\
RF $\times$ WD & 68 & $5.95^{* *}$ & .004 \\
Error $d f$ & 68 & & \\
\hline
\end{tabular}

*** $p<.01$, two-tailed.

$+p<.1$, two-tailed.
Table 3

Study 1 part 2. Means and standard deviations for each experimental condition across dependent variables.

\begin{tabular}{|c|c|c|c|c|c|c|}
\hline & \multicolumn{6}{|c|}{ Work demands } \\
\hline & \multicolumn{3}{|l|}{ Low } & \multicolumn{3}{|l|}{ High } \\
\hline & $M$ & $S D$ & $N$ & $M$ & $S D$ & $N$ \\
\hline \multicolumn{7}{|l|}{$S P T^{\mathrm{a}}$} \\
\hline Promotion focus & 3.65 & .47 & 20 & 4.94 & .49 & 18 \\
\hline Prevention focus & 4.00 & .48 & 19 & 2.94 & .52 & 16 \\
\hline \multicolumn{7}{|l|}{$U U T^{\mathrm{b}}$} \\
\hline Promotion focus & 4.40 & .45 & 20 & 6.22 & .47 & 18 \\
\hline Prevention focus & 4.95 & .46 & 19 & 4.19 & .50 & 16 \\
\hline
\end{tabular}

Snowy Pictures Test.

b Unusual Uses Test.

$\left(F(1,72)=4.40, \quad p=.04 \quad M_{\text {highworkdemands }}=3.09 ; \quad M_{\text {lowworkde }}\right.$ mands $=3.50)$, and no other effects of experimental condition on intrinsic motivation, negative affect, or strain. Finally, the inclusion of the four variables as statistical covariates in the MANOVA did not diminish the effect size of the interaction effect, $F(2,64)=5.77, p=.01$, partial $\left.\eta^{2}=.16\right)$.

Discussion. Overall, we found support for the hypothesized interaction effect. In part 1 we found that trait promotion focus interacted with work demands to predict creative insight. Under high work demands participants with a stronger promotion focus were more creative than participants with a weaker promotion focus. The interaction term including prevention focus was not significant. In part 2 we found that state induced regulatory focus also interacted with work demands to predict creativity in both creative insight and creative generation tasks. Again, participants under high work demands and an induced promotion focus achieved the best scores across both creativity tasks. We also found preliminary evidence suggesting that the moderating effect of regulatory focus on creativity was statistically independent of the effects of intrinsic motivation, strain, and affective states. We did not find a main effect for work demands, which is to some extent consistent with prior literature (Janssen, 2004). Although we did not find a main effect of trait promotion focus, we found that induced promotion focus led to the best creativity outcomes in both tasks, consistent with prior studies (e.g., Friedman \& Förster, 2001).

This study supports the moderating role of regulatory focus across three different tasks, however a critical question is the extent to which these results are generalizable to real work contexts. Thus in the next study we sought to address this by examining creativity in real work settings.

\section{Study 2}

The key objectives of the field study are twofold: First, we seek to replicate the findings from the laboratory in the workplace. In this context we operationalized creativity as the generation of novel and useful ideas in the context of an R\&D project. Secondly, we test our hypotheses not only at the individual level of analysis, but extend our approach to the team level. Given the ubiquity of team working an obvious extension of this research is examining whether the individual level effects manifest at team-level. To this end, we integrate regulatory focus theory, literature on teams as information processors (Hinsz, Tindale, \& Vollrath, 1997) and group dynamics to argue that team regulatory focus influences the extent to which teams will be more or less creative in response to challenge stressors. This two level study addresses previous calls for multilevel research and tests for model homology (Chan, 1998; Hackman, 2003), and also builds on literature examining antecedents of team creativity (e.g., Shin \& Zhou, 2007). 


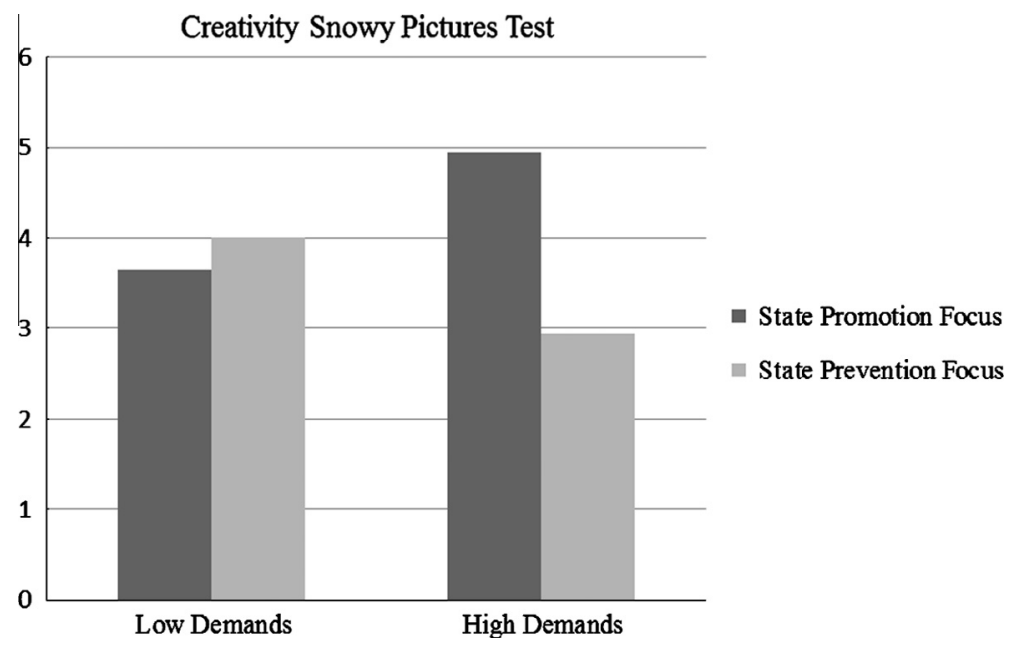

Fig. 2. Study 1 part 2. Interaction effect of work demands and state regulatory focus on the Snowy Pictures Test.

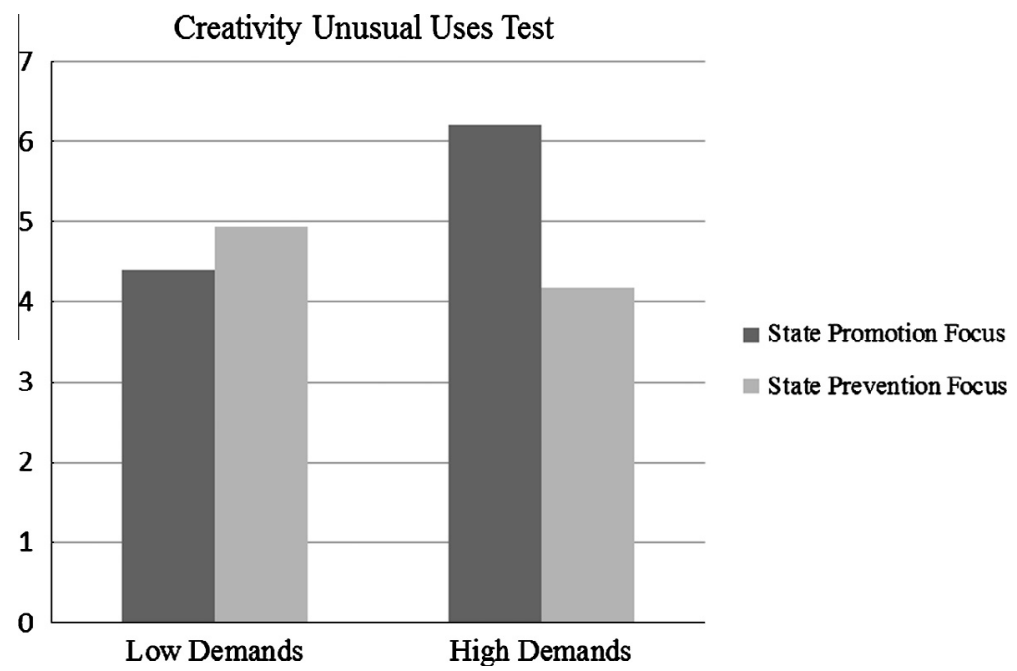

Fig. 3. Study 1 part 2. Interaction effect of work demands and state regulatory focus on the Unusual Uses Test.

\section{Stressors and regulatory focus at the team level}

Stressors have typically been conceptualized as individual level variables. However, given that the way in which individuals appraise a given stressor is influenced by the social context in which individuals are embedded (Hobfoll, 2001), and that members of the same team are typically exposed to similar if not the same stressors, they process them in the same manner, and they display similar responses (Drach-Zahavy \& Freund, 2007; Ellis, 2006; Torrance, 1954), researchers have started to consider them also as team level phenomena. Following this rationale, we conceptualize challenge stressors as a team level construct.

Findings on team level stressors suggest that challenge stressors may disrupt those very team processes that can influence creativity, such as information processing (Hoever, van Knippenberg, van Ginkel, \& Barkema, 2012), transactive memory (Richter, Hirst, van Knippenberg, \& Baer, 2012), and team mental models (Davison \& Blackman, 2005). For instance, teams under time pressure were found to engage in less discussion, thereby reducing information processing (Gladstein \& Reilly, 1985); they were also more likely to lose shared team perspective (Driskell, Salas, \& Johnston, 1999); and to have weaker mental models and transactive memory (Ellis, 2006).
Similarly, although regulatory focus was initially conceptualized and studied as an individual inclination (Higgins, 1997), recent research suggests that it is also an attribute that characterizes teams. Levine, Higgins, and Choi (2000) showed that the behavioral preferences of individuals who work together on a joint task can converge over time to reflect a common focus on either promotion or prevention. Faddegon, Scheepers, and Ellemers (2008) coined the term collective regulatory focus, defined as the promotion or prevention-related goals and strategies that have become part of a group's identity and which direct group members towards promotion or prevention-oriented behavior. In a review of group based-self regulation, Sassenberg and Woltin (2008) concluded that there was convincing evidence of group level regulatory focus and that groups contribute beyond individual predispositions to self-regulation. In addition to its influence on individual behaviors, team regulatory focus can also directly affect team level outcomes, such as team innovation (Rietzschel, 2011).

We focus on team state regulatory focus, conceptualized as an emergent state variable (Marks, Mathieu, \& Zaccaro, 2001), and defined as the team's shared orientation towards promotion or prevention-related goals and strategies. Because theoretical development and research is still in its infancy, we draw on individual regulatory focus theory to propose that team promotion and team 
prevention focus will have implications for how teams respond to challenge stressors. We suggest that the interactive effects of team challenge stressors and regulatory focus occur via changes in group dynamics such as the nature of group communication processes and more risky or conservative patterns of decision making.

Information processing at the group level refers to how information, ideas, or cognitive processes are shared and how these affect group level outcomes (Hinsz et al., 1997). As individuals, teams also process information on the basis of objectives, tasks, or collective goals. These objectives are determined not only by task characteristics but also by characteristics of the team itself, such as, we suggest, the team's regulatory focus. Team objectives will in turn affect which contextual information is given attention to and how this information is encoded, stored and retrieved, culminating in a group response (Hinsz et al., 1997). Application of regulatory focus theory to the team level suggests that the objectives of teams with a predominant promotion focus relate to desired end-states of success, while those of teams with a stronger prevention relate to safety (or risk avoidance) and responsibilities. These differences, we propose, will have implications for how teams respond to challenge stressors.

As groups appear to exaggerate the tendencies of information processing that occur among individuals (group accentuation pattern; Hinsz, 1981), it is plausible to assume that the heuristic, global processing style typical of promotion focus and the systematic, focused processing style associated with preventions focus (Friedman \& Förster, 2000, 2001) translate to the team level, resulting in different group information processing approaches. Indeed, team regulatory focus has been shown to affect the nature of communication in teams (Florack \& Hartmann, 2007). We argue that faced with a perceived opportunity to succeed, promotion focus norms will permit a more global, unstructured exchange of information in which members feel invited to share their perspectives and the discussion rapidly moves from one topic to the next, resulting in a larger number of suggestions being shared (what we refer to as a divergent approach). In contrast, faced with a perceived threat, prevention focus norms will emphasize thoroughness and systematic processing of each suggestion, in order to ensure accuracy and avoid mistakes (Crowe \& Higgins, 1997). Such teams will tend to persevere for longer on the analysis of initial suggestions and discuss a smaller number of possibilities (what we refer to as a convergent approach), leading to a less creative output.

Furthermore, we argue that, consistent with individual level theory, team regulatory focus can also affect the extent to which the teams' decision making in response to challenge stressors is more or less risky, therefore influencing its creativity. Indeed, empirical evidence shows that promotion focus groups make more risky decisions (Florack \& Hartmann, 2007; Levine et al., 2000). Thus we argue that teams with a strong promotion focus are more likely to respond to challenge stressors with more risky solutions, while prevention focus groups are more likely to respond with less risky, already tested solutions, leading respectively to higher and lower levels of creativity.

Formally, we expect that team regulatory focus moderates the impact of team challenge stressors on team creativity in such a way that the relationship becomes positive as team promotion focus strength increases (hypothesis 2a); and becomes negative as team prevention focus strength increases (hypothesis $2 \mathrm{~b}$ ).

\section{Method}

\section{Procedure and sample}

Sixty-one Portuguese organizations involved in a governmental R\&D grant scheme were contacted to participate in the study. Each of the 21 organizations that agreed to participate was asked to appoint a contact person. This contact person was asked to identify the $R \& D$ project team(s) eligible to participate in the study, this participation being conditional on (a) the project having an innovative nature (b) at least two team members working on the project during the week of data collection, and (c) the leader having sufficient contact with the team members to enable him or her to assess their creativity. Given that the level of stressors experienced and the creativity displayed changes over the life cycle of a project, we decided to focus on a 1 week time frame in order to ensure a match between the independent and dependent variables. Thus all key variables except for individual chronic regulatory focus were captured by asking team members and team leaders to focus on a specific week.

The questionnaires were mailed to the contact person in each organization at the beginning of a working week and participants were instructed to complete them on the last day of the working week. All questionnaires were collected by the first author at the start of the following week. Given the small number of eligible participants per team and the announcement of the visit of the investigator to personally collect the questionnaires, all questionnaires were returned except for those of 16 potential participants who had either been on sick leave or who were not participating in the project during the study week. Responses of 150 team members of 57 R\&D teams, and of 51 project leaders, were collected. Sixteen teams were excluded from the analysis as they consisted solely of one project leader and one team member, resulting in a final sample of 41 R\&D teams, including 123 team members and 36 project leaders from 18 organizations.

Team members' average age was 30.8 years, $87.8 \%$ of the participants were male. Average professional tenure was 5.97 years. Doctoral degrees were held by 3.3\%, $8.1 \%$ held a master's degree, $77.2 \%$ a bachelor's degree, and $4.1 \%$ had completed high school. The average age of the 36 project leaders was 32.6 years, $80.5 \%$ were male and average professional tenure was 7.00 years. Doctoral degrees were held by $4.9 \%$ of the project leaders, $17.1 \%$ had a master's degree and $78 \%$ had a bachelor's degree. When translating the items from English to Portuguese the translation-back translation procedure recommended by Brislin (1980) was followed. Two pilot studies assessed R\&D professionals' understanding of the items. The measures included in the study are described below; creativity ratings, creativity requirements, and team tenure were collected from team leaders, while all other measures were completed by team members.

\section{Individual level measures}

\section{Job demands}

We measured job demands using the first six items from Janssen's (2000) job demands scale. Examples are [In the last working week] "I had to work extra hard to finish a task", "I had to work under time pressure". The rating scale was from $1=$ never to $4=a l$ ways; $\alpha=.89$.

\section{Regulatory focus}

Individual regulatory focus was measured using an adaptation of a scale previously developed by Lockwood, Jordan, and Kunda (2002). The scale was initially developed for an academic setting and we reworded the items to better fit the context of an R\&D project. In addition, we omitted items that would not have been relevant within this context, e.g. "I am afraid of the person I might become in the future". The final scale comprised 12 items, six for each orientation. Examples of promotion focus and prevention focus items are respectively "I often think about how I will achieve my work goals" and "I often worry that I will fail to accomplish my work goals". The rating scale ranged from $1=$ not at all like 
me to 9 = very much like me. Cronbach's alphas for promotion and prevention focus were .81 and .76 respectively.

\section{Creativity}

We first selected two widely used creativity scales (George \& Zhou, 2001; Tierney, Farmer, \& Graen, 1999) for a discussion with six project leaders, and based on their input we selected two and developed five additional items. The adapted measure was piloted online using a convenience sample of 146 working people. Examples are [In the last working week, this person] "Demonstrated originality in his/her work", "Suggested feasible ideas for the project". The rating scale ranged from $1=$ not true at all to $7=a b s o-$ lutely true; $\alpha=.90$. The complete scale is included in Appendix.

\section{Team level measures}

\section{Team job demands}

Team job demands were assessed on the same scale as individual job demands but using a team referent instead of an individual referent, following a referent shift model (Chan, 1998). An examples is "We had to work extra hard to finish a task"; $\alpha=.85$.

\section{Team regulatory focus}

Team regulatory focus was assessed by adapting the items used to capture individual regulatory focus to the team level and to the context of a specific project. Items that were not meaningful at the team level were not included (e.g., I often imagine myself experiencing good things that I hope will happen to me). The final scale included nine items, five capturing team promotion $(\alpha=.72)$ and four assessing team prevention focus $(\alpha=.70)$. Examples of items for team promotion and team prevention focus are respectively "We thought about how we would achieve success in this project" and "We worried that we would fail to accomplish our goals for this project". Rating format was from $1=$ not at all like us to $9=$ very much like us.

\section{Team creativity}

Team creativity was assessed on the same scale as individual creativity but using a team referent. Team leaders were asked to rate the team creativity focusing on the last week. An example is "The team demonstrated originality in their work"; $\alpha=.90$.

\section{Control variables}

In order to reduce the probability of confounding factors, a number of variables were included in the analyses as controls. At the individual level we controlled for age, gender and education as these demographic variables have been shown to be associated with creativity (Amabile, 1996). In addition, as hindrance stressors have been found to offset the effects of challenge stressors (Boswell, Olson-Buchanan, \& LePine, 2004), we included role ambiguity as a control hindrance stressor variable (Podsakoff et al., 2007). R\&D professionals told us that this was the most frequent and relevant hindrance stressor in their work context (as compared to politics, red tape, or job insecurity). This was assessed using five items rated on a scale $1=$ totally disagree to $5=$ totally agree (Peterson et al., 1995). An example is "I knew exactly what my responsibilities were" (reverse coded); $\alpha=.88$.

At the team level, team size (De Dreu \& West, 2001), creativity requirements over the week (Unsworth, Wall, \& Carter, 2005), and climate for creativity (Gilson, Mathieu, Shalley, \& Ruddy, 2005), were identified as potential confounding factors and included in the analysis. We assessed team climate for creativity using a three item scale developed by Gilson et al. (2005); $\alpha=.79$. Although all projects required creativity, the extent of this requirement varied across projects and across weeks within projects (Unsworth et al., 2005). In order to control for these differences a one-item measure was developed based on Unsworth et al.' (2005) work. Project leaders were asked to what extent they agreed with the statement "Over the last week, this project required the team to be creative" (scale ranging from $1=$ totally disagree to $7=$ totally agree). Consistent with the rationale for controlling for individual role ambiguity, we also controlled for team role ambiguity when modelling team creativity. This was assessed using the individual level measure described before but using a team referent; $\alpha=.90$. When testing the team model we also controlled for how long the team had been working together in the project (indicated by team leaders), as this could be related to team regulatory focus.

\section{Analytical approach: individual level}

In order to account for the lack of independence in our sample (Kozlowski \& Klein, 2000), we used hierarchical linear modelling to test the lower level relationships (Hofmann, 1997), employing HLM 6.0 (Raudenbush \& Bryk, 2002). This technique allowed us to examine the effects of individual level predictor variables while accounting for variance at higher levels. Job demands, promotion focus, prevention focus and controls were the individual level (level 1) variables. Team control variables were included at the group level (level 2). To facilitate comparisons of the magnitudes of effects stemming from differently scaled variables we standardized all individual and team level variables. We report unstandardized weights for all relationships (cf. Mathieu, Maynard, Taylor, Gilson, \& Ruddy, 2007). Note that sample size was slightly reduced due to listwise deletion. A hybrid correlation matrix between all study variables including means and standard deviations is presented in Table 4.

\section{Results}

We ran a CFA to confirm that climate for creativity, role ambiguity, job demands, promotion focus and prevention focus represented five distinct constructs. The five-factor model $\left(\chi^{2}(285)=424.29, p=.00, C F I=.90, R M S E A=.06\right)$ fit the data better than the following models: a four-factor model collapsing promotion and prevention focus $\left(\chi^{2}(289)=511.04, p=.00, C F I=.84\right.$, $R M S E A=.08)$; a second four-factor model collapsing challenge and hindrance stressors $\left(\chi^{2}(289)=790.54, p=.00, \quad C F I=.64\right.$, $R M S E A=.12$ ); a three-factor model collapsing both the two stressors and the two regulatory foci into two separate factors $\left(\chi^{2}(293)=920.59, p=.00, C F I=.55, R M S E A=.14\right)$; and a one-factor model $\left(\chi^{2}(295)=1188.232, p=.00, C F I=.36\right.$, RMSEA $\left.=.16\right)$.

Table 5 presents results of a three-level HLM analysis examining the effects of job demands and regulatory focus on individual creativity. Analysis of a null model revealed that $56.04 \%$ of the variance in individual creativity was accounted by group-level factors, justifying he adoption of analytical hierarchical linear procedures. Individual level factors accounted for $43.91 \%$ of the variance, while organizational factors explained no variance. Consequently, although we adopted a 3-level model for the sake of consistency with the analysis of team creativity described next, calculations of $R^{2}$ were conducted only taking into account individual and group levels. We tested the hypotheses firstly by regressing creativity on the individual (Model 1) and team level control variables (Model 2). In a third step we entered the individual level predictors (Model 3). In the final step we entered the interaction terms (Model 4). No control variables were added at the organizational level.

We found support for the existence of moderation effects. Results indicated that both promotion focus $(\gamma=.21, p=.004)$ and prevention focus $(\gamma=-.22, p=.007)$ interacted with job demands to predict creativity (Table 5 ). In relation to the interaction between job demands and promotion focus, the simple slope was -.33 at $-1 S D$ of promotion focus $(p=.011)$ and .08 at $+1 S D(n s)$. 
In relation to prevention focus, the simple slope was .09 at $-1 S D$ $(n s)$ and -.35 at $+1 S D(p=.023)$. As can be seen in Fig. 4 , the relationship between job demands and creativity is negative when promotion focus is low. Fig. 5 shows that the relationship between job demands and creativity is negative when prevention focus is high. There were no main effects of either job demands or regulatory focus.

\section{Analytical approach: team level}

We examined whether our team-level constructs met the statistical criteria for aggregation (Kozlowski \& Klein, 2000) by calculating within team agreement $\left(R_{\mathrm{wg}}(j)\right.$; James, Demaree, \& Wolf, 1984), intraclass correlation statistics ICC (1), and the amount of withingroup variance. The results presented in Table 6 show that overall the required criteria were met, although we note that support is only modest for team prevention focus.

We tested team level hypotheses following the same procedure as described for individual creativity, having now teams as level-1 units nested in organizations, at level-2. A null model showed that team factors accounted for $89 \%$ of the variance in team level creativity while organizational level factors accounted for only $11 \%$ of the variance. We first entered the control variables (Model 1), then team job demands and team regulatory focus (Model 2), followed by the two interaction terms (Model 3).

\section{Results}

We ran a CFA to confirm that climate for creativity, team role ambiguity, team job demands, team promotion focus and team prevention focus represented five distinct constructs. The five-factor model $\left(\chi^{2}(217)=327.29, p=.00, C F I=.91, R M S E A=.06\right)$ fit the data better than the following models: a four-factor model collapsing promotion and prevention focus $\left(\chi^{2}(221)=461.55, p=.00\right.$, $C F I=.80, R M S E A=.10)$; a second four-factor model collapsing challenge and hindrance stressors $\left(\chi^{2}(221)=706.68, p=.00, C F I=.59\right.$, RMSEA = .14); a three-factor model collapsing both the two stressors and the two regulatory foci into two separate factors $\left(\chi^{2}(224)=837.68, p=.00, C F I=.49, R M S E A=.16\right)$; and a one-factor model $\left(\chi^{2}(227)=969.85, p=.00, C F I=.38, R M S E A=.17\right)$. As we found an unexpectedly high correlation between team job demands and team prevention focus we also tested an alternative 4-factor model collapsing these variables, but this structure had a poor fit $\left(\chi^{2}(221)=361.04, p=.00, C F I=.88, R M S E A=.08\right)$.

Results displayed in Table 7 reveal that team job demands interacted with team promotion focus $(\gamma=.43, p=.006)$ to predict creativity, but not with team prevention focus $(\gamma=-.14, n s)$. An inspection of the simple slopes revealed that the simple slope for promotion focus was .64 at $+1 S D(p=.004)$; and -.22 at $-1 S D$ $(n s)$. As team promotion focus increases, the relationship between job demands and creativity becomes stronger, supporting hypothesis 2a (Fig. 6).

\section{Discussion}

Overall, these results corroborate the findings of the experimental study. As in study 1 , we found that individual regulatory focus moderates the effects of challenge stressors on creativity. The pattern was however slightly different than anticipated: while we had expected that there would be a positive effect of job demands for individuals with a strong promotion focus, job demands had a negative effect on creativity among individuals with either a weak promotion focus or a strong prevention focus. Creativity was unaffected by job demands for people with a strong promotion and for people with a weak prevention focus. While the moderating effect of prevention focus manifested as expected, we were surprised by 
Table 5

Study 2. HLM results for interactions of job demands with regulatory focus on individual creativity.

\begin{tabular}{|c|c|c|c|c|c|c|c|c|}
\hline \multirow[t]{2}{*}{ Variable } & \multicolumn{2}{|l|}{ Model 1} & \multicolumn{2}{|l|}{ Model 2} & \multicolumn{2}{|l|}{ Model 3} & \multicolumn{2}{|l|}{ Model 4} \\
\hline & $\gamma$ & $S E$ & $\gamma$ & $S E$ & $\gamma$ & $S E$ & $\gamma$ & $S E$ \\
\hline \multicolumn{9}{|l|}{ Level 1: Control variables } \\
\hline Intercept & $3.25^{* *}$ & .47 & $2.95^{* *}$ & .53 & $3.16^{* *}$ & .47 & $2.89^{* *}$ & .48 \\
\hline Gender & .35 & .22 & $.51^{\dagger}$ & .30 & $.40^{\dagger}$ & .23 & $.57^{*}$ & .22 \\
\hline Age & $.17^{\dagger}$ & .10 & $.17^{\dagger}$ & .10 & $.19^{\dagger}$ & .10 & $.20^{*}$ & .10 \\
\hline Education & .05 & .10 & .09 & .09 & .09 & .10 & .08 & .08 \\
\hline Role ambiguity & .18 & .10 & $.21^{*}$ & .12 & $.25^{*}$ & .10 & $.27^{*}$ & .10 \\
\hline \multicolumn{9}{|l|}{ Level 2: Control variables } \\
\hline Team size & & & $-.23^{*}$ & .10 & -.21 & .11 & $-.23^{*}$ & .10 \\
\hline Climate for creativity & & & $.38^{* *}$ & .11 & $.37^{*}$ & .12 & $.39^{*}$ & .12 \\
\hline Creativity requirements & & & $.54^{* *}$ & .16 & $.58^{* *}$ & .18 & $.59^{*}$ & .16 \\
\hline \multicolumn{9}{|l|}{ Level 1: Main effects } \\
\hline Job demands (JD) & & & & & -.07 & .12 & -.12 & .09 \\
\hline Promotion focus (PROM) & & & & & .04 & .12 & .05 & .11 \\
\hline Prevention focus (PREV) & & & & & -.15 & .10 & -.10 & .09 \\
\hline \multicolumn{9}{|l|}{ Level 1: Interaction effects } \\
\hline $\mathrm{JD} \times \mathrm{PROM}$ & & & & & & & $.21^{* *}$ & .07 \\
\hline $\mathrm{JD} \times \mathrm{PREV}$ & & & & & & & $-.22^{* *}$ & .09 \\
\hline$\chi^{2}$ & 200.39 & & 110.67 & & 124.02 & & 37.05 & \\
\hline Model deviance & 317.18 & & 295.73 & & 292.31 & & 285.14 & \\
\hline$R^{2}$ within groups & .04 & & .08 & & .15 & & .22 & \\
\hline$R^{2}$ between groups & .00 & & .53 & & .48 & & .50 & \\
\hline$R^{2}$ total & .02 & & .33 & & .34 & & .38 & \\
\hline
\end{tabular}

Note. Individuals $N=106$, Teams $N=40$, Organizations, $N=18$.

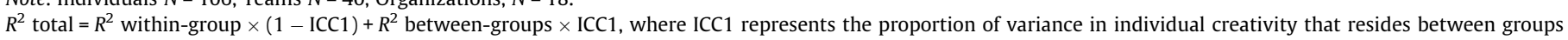
(.56).

${ }^{\dagger} p<.1$, two-tailed tests of significance.

* $p<.05$, two-tailed tests of significance.

${ }^{*} p<.01$, two-tailed tests of significance.

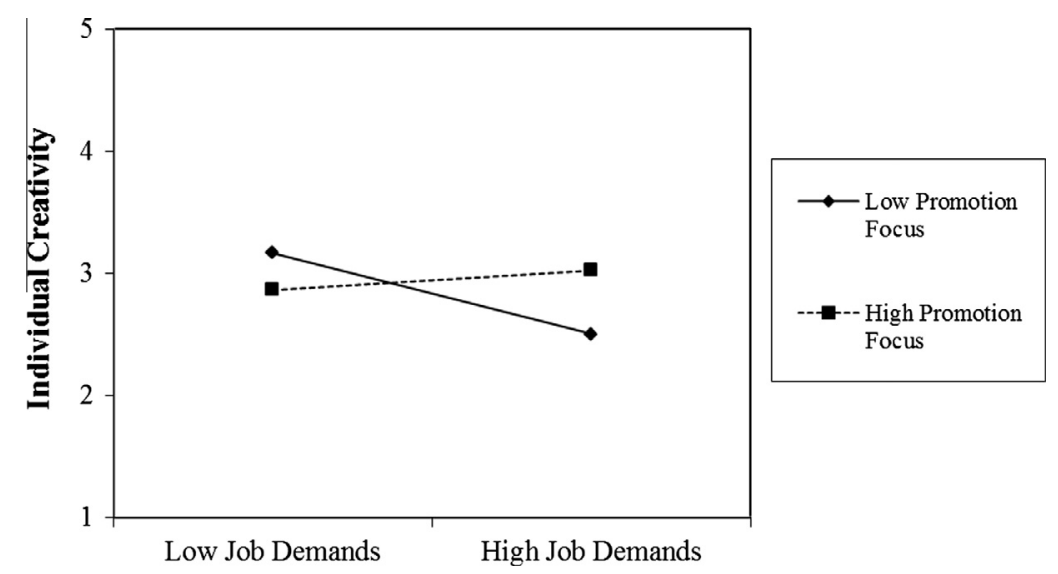

Fig. 4. Study 2. Interaction effect of job demands and promotion focus on individual creativity.

the pattern of results for promotion focus. The non-significant high-promotion slope cannot easily be accounted for, but inspection of the average level of promotion focus (range 1 - 9; sample Mean $=6.50, S D=1.22$, cf. Table 4 ) raises the question whether high scores of promotion focus were, in this specific work context, high enough to exert their enhancing effect. This issue needs to be examined in future research, but overall the results strongly corroborate the proposed moderator role of individual regulatory focus.

We also found support for the impact of team regulatory focus on the relationship between team job demands and team creativity. When facing high job demands, teams with a strong promotion focus were more creative; however, no effect was found for prevention focus, failing to support hypothesis $2 \mathrm{~b}$. The level of within-team agreement of prevention focus was fairly low; which could mean that prevention focus was in fact not a team-level phenomenon. Alternatively, prevention focus maybe is simply not a moderator of work demands at the team level, or its effect is weaker and our sample size did not give sufficient statistical power to detect it.

We did not find a main effect of challenge stressors on individual or team creativity, in line with previous research (e.g. Janssen, 2000). Although team prevention focus had a marginally significant negative effect on team creativity, we did not find a main positive effect of promotion focus on individual or team creativity which is surprising, although not unprecedented (Neubert, Kacmar, Carlson, Chonko, \& Roberts, 2008). This suggests that the effects of regulatory focus on creativity are likely to be influenced by other contextual factors that might enhance or buffer the expression of internal dispositions (Mischel, 1977; Tett \& Burnett, 2003). 




Fig. 5. Study 2. Interaction effect of job demands and prevention focus on individual creativity.

Table 6

Study 2. Aggregation indices for team-level variables.

\begin{tabular}{llll}
\hline Team variable & $R_{\mathrm{wg}}(j)$ & $\mathrm{ICC}(1)$ & $\begin{array}{l}\text { Proportion of within group } \\
\text { variance }(\%)\end{array}$ \\
\hline Team job demands & .82 & .89 & 32.49 \\
Team promotion focus & .85 & .19 & 17.96 \\
Team prevention focus & .65 & .14 & 12.24 \\
Team climate for creativity & .85 & .22 & 23.71 \\
Team role ambiguity & .70 & .29 & 27.95 \\
\hline
\end{tabular}

\section{General discussion}

The objective of the present research was to address the inconsistent effects of challenge stressors on creativity by integrating self-regulation theory and the challenge-hindrance stressors framework. We proposed that regulatory focus influences the ex- tent to which challenge stressors such as job demands are positively or negatively related to creativity. We hypothesized that the relationship between challenge stressors and creativity becomes positive as promotion focus increases, while it becomes negative as prevention focus increases.

Across two studies we found support for our overarching interaction hypothesis. Using both experimental data gathered from students and correlational data collected in a work setting, we demonstrated that the impact of job demands on creativity depended on regulatory focus. The experimental study showed that, across different creativity tasks, individuals with either a stronger dispositional or an induced promotion focus were more creative in a high work demands condition. Field data gathered from professionals in R\&D teams showed that the relationship between individual job demands and individual creativity was negative for individuals with either a weaker trait promotion focus or a stronger trait prevention focus.

Table 7

Study 2. HLM results for interactions of team job demands with team regulatory focus on team creativity.

\begin{tabular}{|c|c|c|c|c|c|c|}
\hline \multirow[t]{2}{*}{ Variable } & \multicolumn{2}{|l|}{ Model 1} & \multicolumn{2}{|l|}{ Model 2} & \multicolumn{2}{|l|}{ Model 3} \\
\hline & $\gamma$ & $S E$ & $\gamma$ & $S E$ & $\gamma$ & $S E$ \\
\hline \multicolumn{7}{|l|}{ Level 1: Control variables } \\
\hline Intercept & $4.07^{* *}$ & .19 & $4.07^{* *}$ & .18 & $4.08^{* *}$ & .19 \\
\hline Team size & $-.12^{*}$ & .07 & $-.11^{* *}$ & .09 & $-.17^{*}$ & .07 \\
\hline Project tenure & .10 & .09 & .22 & .15 & .18 & .17 \\
\hline Climate for creativity & $.57^{* *}$ & .12 & $.57^{* *}$ & .10 & $.79^{* * *}$ & .08 \\
\hline Creativity requirements & $.39^{* *}$ & .09 & $.42^{* *}$ & .08 & $.27^{*}$ & .11 \\
\hline Team role ambiguity & .17 & .16 & .05 & .20 & $.34^{*}$ & .16 \\
\hline \multicolumn{7}{|l|}{ Level 1: Main effects } \\
\hline Job demands (JD) & & & .14 & .21 & .21 & .21 \\
\hline Team promotion focus (TPROM) & & & -.12 & .14 & -.07 & .09 \\
\hline Team prevention focus (TPREV) & & & $-.37^{\dagger}$ & .21 & -.17 & .18 \\
\hline \multicolumn{7}{|l|}{ Level 1: Interaction effects } \\
\hline $\mathrm{JD} \times \mathrm{TPROM}$ & & & & & $.43^{* *}$ & .15 \\
\hline $\mathrm{JD} \times \mathrm{TPREV}$ & & & & & -.14 & .12 \\
\hline$\chi^{2}$ & 41.03 & & 37.37 & & 69.86 & \\
\hline Model deviance & 108.70 & & 111.27 & & 108.19 & \\
\hline$R^{2}$ within-organizations & .50 & & .50 & & .66 & \\
\hline$R^{2}$ between-organizations & 0 & & 0 & & 0 & \\
\hline$R^{2}$ total & .45 & & .44 & & .59 & \\
\hline
\end{tabular}

Note. Teams $N=40$, Organizations $N=18$.

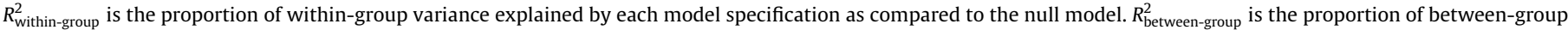
variance explained by the model specification as compared to the null model.

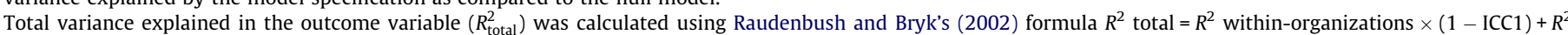
between-organizations $\times$ ICC1, where ICC1 represents the proportion of variance in team creativity that resides between organizations (.11).

${ }^{\dagger} p<.1$, two-tailed tests of significance.

${ }^{*} p<.05$, two-tailed tests of significance.

${ }^{*} p<.01$, two-tailed tests of significance. 




Fig. 6. Study 2. Interaction effect of team job demands and team promotion focus on team creativity.

In addition, we also suggested that the moderator role of regulatory focus can be generalized across levels of analysis. Based on the conceptualization of teams as information-processors (Hinsz et al., 1997), we proposed that team promotion and prevention foci moderate the effect of team challenge stressors. Our results showed that teams with a strong promotion focus were rated as more creative by their line managers, although we did not find the expected effect for team prevention focus.

What might be the underlying mechanisms of these moderation effects? We suggest that the moderating effect of regulatory focus is a consequence of the different goals, perception focus, processing styles and behavioral approaches associated with each focus. An alternative explanation, derived from the challenge-hindrance framework, relates to intrinsic motivation and strain playing a mediating role since both variables influence creativity (Amabile, 1996; Van Dyne, Jehn, \& Cummings, 2002). It could be argued that the view of challenge stressors as an opportunity for ideal achievement associated with promotion focus accentuates the positive relationship between challenge stressors and intrinsic motivation, and consequently increases creativity. In contrast, the view of challenge stressors as requiring 'oughts' fulfilment and loss avoidance, elicited by prevention focus, can be hypothesized to enhance the positive relationship between challenge stressors and strain, and in turn impair creativity. Taken together, this would suggest a moderated mediation model in which the first paths between the independent variable (challenge stressors) and mediators (intrinsic motivation and strain) are moderated by promotion and prevention focus, respectively (cf., Brenninkmeijer, Demerouti, le Blanc, \& van Emmerik, 2010).

However, our experimental study showed that the interactive effects of regulatory focus were not mediated by either intrinsic motivation or strain. In other words, when facing challenge stressors individuals with a stronger promotion focus are not more creative simply because they enjoy the task more. The influence of regulatory focus on the challenge stressors-creativity link is likely to rely more upon cognitive rather than motivational processes. However, we need to keep in mind that we captured only one aspect of motivation (intrinsic motivation) and one dimension of affect (valence), and research has shown that other facets of motivation (e.g., prosocial motivation; Grant \& Berry, 2011) and affect (e.g., activation; Baas, De Dreu, \& Nijstad, 2008) are also important for creativity. Future research might explore the extent to which affective, motivational and cognitive processes are differentially implicated in the interactions we found between challenge stressors, regulatory focus and creativity.

Although we consistently found an interaction effect between demands and individuals' regulatory focus on creativity, the pat- tern of this interaction varied across the experimental and field studies. In the experimental study, both trait promotion focus and the induced promotion focus triggered the positive effects of demands; the same applies to the team promotion focus in the field study. The effect, however, of individuals' work-related trait regulatory focus in the field study departed from this pattern. We suggested above that this may be a result of the magnitude of the individual trait promotion focus. It is possible that trait promotion focus did not reach the level necessary in our sample for demands to enhance creativity, and that, consequently, regulatory focus only acted as a buffer of the negative effect of demands.

An alternative explanation is that other variables that we did not measure might have affected the strength and nature of the interaction pattern in work settings, speaking for a three-way interaction. Existence of required resources might be one such factor. It is possible that due to lack of resources (e.g., materials, instruments) a strong promotion focus can only go as far in helping individuals facing high demands not to lower their creativity, which occurs if promotion focus is low. Another plausible factor is the level of autonomy individuals have in carrying out their tasks. If individuals have little autonomy, they are limited in the extent to which they can bring about creative change. Thus, even a strong promotion focus can do little in terms of promoting creativity in the face of challenge stressors, while a weak promotion focus will lead to impaired creativity. We can speculate that the reason why we did not find any alteration in the pattern of the interaction for promotion focus at the team level is because teams, as a whole, are likely to have higher autonomy and resources than each individual team member on his or her own, and thus there was no change in the nature of the interplay between team promotion focus and team challenge stressors. Future research should examine these and other potential factors that might influence the nature and strength of the interplay between challenge stressors and regulatory focus, given the practical and theoretical importance of these relationships. This approach would allow us to extend our knowledge by providing a better understanding of when regulatory focus is more or less instrumental in changing the effects of challenge stressors on creativity. We do however note that this difference in patterns has no impact in terms of practical implications. Although the patterns are different, the underlying conclusion, and associated implications, are the same: when facing challenge stressors, a promotion focus will be beneficial for creativity.

\section{Theoretical contribution}

Previous theoretical models have offered contradictory predictions regarding the effect of stressors on creativity (e.g., Gardner, 
1986; Vecchio, 1990), and these contradictory predictions have been reflected in inconsistent empirical results (Amabile et al., 2002; Ohly \& Fritz, 2010). The key contribution of this study is revealing how we may begin to account for previously inconsistent findings about the relationship between challenge stressors and creativity. Our research proposed and found evidence for the proposition that this relationship is better understood by invoking a self-regulatory perspective. We focused on a type of stressor that has large variations in its effects (Gilboa et al., 2008), and we were able to explain these variations in effects as a function of selfregulation. The fundamental nature of regulatory focus encompasses a number of environmental responses, such as perception, goal pursuit, information processing, and behavioral reactions (Crowe \& Higgins, 1997; Higgins, 1997). Thus, it has potential to provide an integrated explanation of how challenge stressors influence creativity in the workplace. In addition, the theory suggests that prevention and promotion foci produce quite opposite effects in relation to these affective, motivational, perceptual and behavioral processes, and as our findings suggest, the theory might well offer the key to explain previous contradictory findings. Our study therefore offers a new and potentially powerful perspective on our understanding of the relationship between challenge stressors and creativity.

Our finding also contributes to other frameworks and research perspectives. First, we contribute to creativity research by providing complementary knowledge about how individual and contextual characteristics interact to affect creativity (cf. Woodman et al., 1993). We also add to a small but growing literature examining the antecedents of team creativity (Shin \& Zhou, 2007). Second, we extend the challenge-hindrance stressors framework by analysing the extent to which regulatory focus can modify the impact of challenge stressors. Third, by testing our model at both the individual and team levels, we respond to calls of multilevel researchers for a more comprehensive understanding of how phenomena unfold at different levels of analyses.

\section{Practical implications}

Our results also have significant practical implications. High levels of job demands are ubiquitous and also common in many jobs requiring creativity (e.g., Bowers, 2007; Wall et al., 1997). An awareness that this is not necessarily detrimental for creativity empowers managers to transform challenge stressors into drivers for creativity. Our experimental study showed that an induced momentary promotion focus enhances creativity when people are exposed to high work demands, suggesting that how managers frame expectations makes a difference to employee creativity. Indeed, other experimental work has shown that simple differences in how a task is framed influence momentary regulatory focus, reinforcing our optimism about the malleability of regulatory focus and thereby employee creativity. Focusing our attention on the potential gains or non-gains in contrast to losses or non-losses in a situation influences momentary regulatory focus (Liberman et al., 2001 ) in a way that is likely to elicit employee creativity.

These results are also important for managers responsible for coordinating team work, as team promotion focus can also lead to team creativity in response to high levels of job demands. Managers who want their teams to respond creatively in situations of high challenge stressors should ensure team promotion focus is the dominant team orientation. Findings on the factors that shape the nature of team regulatory focus provide suggestions for the strategies that managers can use to influence team regulatory focus (Levine et al., 2000; see also Faddegon, Ellemers, \& Scheepers, 2009). In addition to this, Kark and Van Dijk (2007) proposed that a leader's chronic regulatory focus can also prime followers' situa- tional regulatory focus. This requires leaders to be aware of their own regulatory focus and to act accordingly.

\section{Limitations and strengths}

Because the field study was cross-sectional, we cannot offer confident conclusions about causality. Balanced against this is the fact that the experimental studies showed the same interaction effect as those found in the field study, suggesting they might well be sustained in a longitudinal study. The size and number of teams in the field study was relatively small and so future research is needed to verify whether these results can be replicated in larger samples and whether greater statistical power offers a clearer picture of the interaction effects. Finally, the support for aggregation of prevention focus at the team level was modest. Although scale reliability was acceptable and CFA results indicated a good fit, this weak support suggests the measurement of this variable at the team level needs to be improved, or that teams do not develop a team prevention focus to the extent that they develop a team promotion focus.

In relation to the experimental study, we should note that our manipulation check of regulatory focus consisted only of a request for participants to recall the manipulation and we did not measure state regulatory focus. This is consistent with the majority of previous studies, which have typically either not included a manipulation check (e.g., Friedman \& Förster, 2001), or looked instead for indicators of the extent to which participants had successfully completed the manipulation task (e.g., Leonardelli et al., 2007). Given that we applied one of the most widely used manipulations of regulatory focus (essay about ideals/oughts; cf. Liberman et al., 1999) and that the pattern of results supports our hypotheses, we are confident that regulatory focus was successfully induced. Another issue to consider is whether participants' creativity in part 2 of the experiment might have been affected by their performance in part 1 . However, given that participants had no patterns of comparison against which to evaluate their creative performance in part 1 , it is unlikely that they were able to draw any inferences that could affect their subsequent creative performance. Finally, although we have made significant progress in this research in exploring the underlying mechanisms accounting for the interaction effect, our results are still preliminary. More experimental research is needed to discover precisely the underlying cognitive, affective, motivational and behavioral mechanisms involved in the interactions.

Despite its limitations, there are also a number of methodological strengths worthy of notice. First, we tested our hypotheses in both experimental and field settings, which aids in ensuring both internal and external validity. Second, we avoided issues related to common method variance by using different data sources. Third, employing different operationalizations of regulatory focus and finding a similar pattern of results across the studies suggests robustness in the effects. Finally, by capturing different elements of creativity we ensure the generalizability of results across different domains of creative endeavour.

\section{Future research directions}

Even though previous theorizing and empirical research has supported the view of challenge stressors as having a generalized positive effect on relevant work related outcomes, our study shows that individuals' regulatory approach has to be taken into account in order to better understand the impact of challenge stressors on creativity. Future research can adopt these same lenses in order to examine the effects of other stressors that have large variations in effect sizes, such as environmental uncertainty (credibility interval of -.52 to .30; cf. Gilboa et al., 2008). Likewise, our approach could 
be expanded to test the effects of demands and other challenge stressors on work outcomes such as performance, OCB, and turnover intentions. For instance, previous theorizing and empirical evidence has linked regulatory focus to OCB (Dewett \& Denisi, 2007; Neubert et al., 2008). It is also possible that the different approaches elicited by promotion and prevention foci in response to challenge stressors will affect the extent to which individuals engage in more (or less) OCB or deviant behaviors.

Because research on regulatory focus at the team level is still beginning to emerge, we can advance only tentative explanations for the processes underlying the work demands-regulatory focus interplay. Although there is an analogy between individual and team level processes suggestive of an isomorphic model (Chan, 1998; Kozlowski \& Klein, 2000), there are also critical differences. We argued that the interactive effects of team regulatory focus occur via changes in group dynamics such as the nature of group communication processes and the nature of group decision making. Future research could test this proposition by exploring whether a more divergent approach (promotion focus) or more convergent approach (prevention focus) to group discussion as well as more risky or more conservative patterns of decision making are a function of the interplay of demands and group regulatory focus.

Also, our research adopted a multi-level perspective on the theoretical challenges we identified, demonstrating a degree of homology. Extending regulatory theory to the level of organizational culture might be a fruitful avenue for further research. If an organizational culture has a strong promotion value, this might well have an impact on organizational innovation when competition increases. However, a culture characterized by prevention values could decrease its levels of organizational innovation in response to competition, thereby threatening its survival all the more. It would also be useful to assess the interactive effects of regulatory focus, work demands and creativity at different levels of organizational hierarchy to determine whether seniority is associated with stronger effects. Because more senior teams have more power and autonomy, team promotion focus might have stronger effects on creativity than amongst teams lower in the organizational hierarchy.

Finally, our research involved R\&D teams, a context in which creativity is typically required. It would also be relevant to test whether these effects generalize to contexts in which creativity is not so overtly driven by job requirements (Unsworth, 2001), such as manufacturing or customer service. Although our theoretical rationale would apply in the same way in such contexts, only an empirical test would allow to clearly reach conclusions about its validity in these settings.

In sum, our findings not only contribute to current research by specifying more clearly the conditions under which challenge stressors can lead to creativity, but they also have broader implications for managers who wish their employees to be creative in response to high job demands. In the context of work where creativity and innovation are highly valued and often vital for organizational survival, the discovery that regulatory focus may play a key role in employees and teams responding to challenging job demands is important. It both suggests why previous research has often produced contradictory findings and suggests valuable managerial strategies for promoting workplace creativity in the future.

\section{Appendix. Creativity scale}

Please indicate to what extent the following statements are true.

In the last working week, this person. .
Suggested many ideas.

Actively suggested new possibilities for the project.

Suggested new ideas concerning varied aspects of the project.

Suggested very diverse ideas.

Suggested feasible ideas for the project.

Generated novel, but operable work-related ideas.

Demonstrated originality in his/her work.

Rating scale ranged from $1=$ not true at all to $7=$ absolutely true; $\alpha=.90$.

\section{References}

Amabile, T. M. (1988). A model of creativity and innovation in organizations. In B. M. Staw \& L. L. Cummings (Eds.). Research in organizational behavior (Vol. 10, pp. 123-167). Grenwich, CT: JAI Press.

Amabile, T. M. (1996). Creativity in context: Update to the social psychology of creativity. Boulder, CO: Westview.

Amabile, T. M., Mueller, J. S., Simpson, W. B., Hadley, C. N., Kramer, S. J., \& Fleming, L. (2002). Time pressure and creativity in organizations: A longitudinal field study. Harvard Business School Working Paper Series, No. 02-073.

Andrews, F. M., \& Farris, G. F. (1972). Time pressure and performance of scientists and engineers: A five-year panel study. Organizational Behavior and Human Performance, 8, 185-200.

Aryee, S., Zhou, Q., Sun, L. Y., \& Lo, S. (2009). Perceptions of politics, intrinsic motivation and creative performance: Evidence from the service sector. In Academy of Management Annual Meeting Proceedings (pp. 1-6).

Baas, M., De Dreu, C. K. W., \& Nijstad, B. A. (2008). A meta-analysis of 25 years of mood-creativity research: Hedonic tone, activation, or regulatory focus? Psychological Bulletin, 134, 779-806.

Boswell, W. R., Olson-Buchanan, J. B., \& LePine, M. A. (2004). Relations between stress and work outcomes: The role of felt challenge, job control, and psychological strain. Journal of Vocational Behavior, 64, 165-181.

Bowers, T. (2007). The top workplace stressors and irritations. <http:// www.techrepublic.com/blog/career/the-top-workplace-stressors-andirritations/210>.

Brenninkmeijer, V., Demerouti, E., le Blanc, P. M., \& van Emmerik, I. J. H. (2010). Regulatory focus at work: The moderating role of regulatory focus in the job demands-resources model. The Career Development International, 15, 708-728.

Brislin, R. W. (1980). Translation and content analysis of oral and written material. In H. C. Triandis \& J. W. Berry (Eds.). Handbook of cross-cultural psychology (Vol. 1, pp. 389-444). Boston: Allyn \& Bacon.

Byron, K., Khazanchi, S., \& Nazarian, D. (2010). The relationship between stressors and creativity: A meta-analysis examining competing theoretical models. Journal of Applied Psychology, 95, 201-212.

Caplan, R., Cobb, S., French Jr., J., Van Harrison, R., \& Pinneau, S. (1975). Job demands and worker health: Main effective and occupational difference. Washington, DC: US Government Printing Office.

Cavanaugh, M. A., Boswell, W. R., Roehling, M. V., \& Boudreau, J. W. (2000). An empirical examination of self-reported work stress among US managers. Journal of Applied Psychology, 85, 65-74.

Chan, D. (1998). Functional relations among constructs in the same content domain at different levels of analysis: A typology of composition models. Journal of Applied Psychology, 83, 234-246.

Crowe, E., \& Higgins, E. T. (1997). Regulatory focus and strategic inclinations: Promotion and prevention in decision-making. Organizational Behavior and Human Decision Processes, 69, 117-132.

Davison, G., \& Blackman, D. (2005). The role of mental models in innovative teams. European Journal of Innovation Management, 8, 409-423.

De Dreu, C. K. W., \& West, M. A. (2001). Minority dissent and team innovation: The importance of participation in decision making. Journal of Applied Psychology, 86, 1191-1201.

Drach-Zahavy, A., \& Freund, A. (2007). Team effectiveness under stress: A structural contingency approach. Journal of Organizational Behavior, 28, 423-450.

Dewett, T. (2007). Linking intrinsic motivation, risk taking, and employee creativity in an R\&D environment. RED Management, 37, 197-208.

Dewett, T., \& Denisi, A. S. (2007). What motivates organizational citizenship behaviours? Exploring the role of regulatory focus theory. European Journal of Work and Organizational Psychology, 16, 241-260.

Driskell, J. E., Salas, E., \& Johnston, J. H. (1999). Does stress lead to a loss of team perspective? Group Dynamics: Theory, Research, and Practice, 3, 291-302.

Ekstrom, R. B., French, J. W., \& Harman, H. H. (1976). Manual for factor referenced cognitive tests. Princeton, NJ: Educational Testing Service.

Ellis, A. P. J. (2006). System breakdown: The role of mental models and transactive memory in the relationship between acute stress and team performance. Academy of Management Journal, 49, 576-589.

Faddegon, K., Ellemers, N., \& Scheepers, D. (2009). Eager to be the best, or vigilant not to be the worst: The emergence of regulatory focus in disjunctive and conjunctive group tasks. Group Processes and Intergroup Relations, 12, 653-671.

Faddegon, K., Scheepers, D., \& Ellemers, N. (2008). If we have the will, there will be a way: Regulatory focus as a group identity. European Journal of Social Psychology, $38,880-895$. 
Fay, D., \& Sonnentag, S. (2002). Rethinking the effects of stressors: A longitudinal study on personal initiative. Journal of Occupational Health Psychology, 3 221-234.

Florack, A., \& Hartmann, J. (2007). Regulatory focus and investment decisions in small groups. Journal of Experimental Social Psychology, 43, 626-632.

Freitas, A. L., Liberman, N., Salovey, P., \& Higgins, E. T. (2002). When to begin? Regulatory focus and initiating goal pursuit. Personality and Social Psychology Bulletin, 28, 121-130.

Friedman, R. S., \& Förster, J. (2000). The effects of approach and avoidance motor actions on the elements of creative insight. Journal of Personality and Social Psychology, 79, 477-492.

Friedman, R. S., \& Förster, J. (2001). The effects of promotion and prevention cues on creativity. Journal of Personality and Social Psychology, 81, 1001-1013.

Friedman, R. S., \& Förster, J. (2002). The influence of approach and avoidance motor actions on creative cognition. Journal of Experimental Social Psychology, 38, 41-55.

Gardner, D. G. (1986). Activation theory and task design: An empirical test of several new predictions. Journal of Applied Psychology, 71, 411-418.

George, J. M., \& Zhou, J. (2001). When openness to experience and conscientiousness are related to creative behavior: An interactional approach. Journal of Applied Psychology, 86, 513-524.

Gilboa, S., Shirom, A., Fried, Y., \& Cooper, C. (2008). A meta-analysis of work demand stressors and job performance. Examining main and moderating effects. Personnel Psychology, 61, 227-271.

Gilson, L. L., Mathieu, J. E., Shalley, C. E., \& Ruddy, T. M. (2005). Creativity and standardization: Complementary or conflicting drivers of team effectiveness? Academy of Management Journal, 48, 521-531.

Gladstein, D., \& Reilly, N. P. (1985). Group decision making under threat: The tycoon game. Academy of Management Journal, 28, 613-627.

Grant, A. M., \& Berry, J. W. (2011). The necessity of others is the mother of invention: Intrinsic and prosocial motivations, perspective taking, and creativity. Academy of Management Journal, 54, 73-96.

Hackman, J. R. (2003). Learning more by crossing levels: Evidence from airplanes, hospitals, and orchestras. Journal of Organizational Behavior, 24, 905-922.

Hamstra, M. R. W., Bolderdijk, J. W., \& Veldstra, J. L. (2011). Everyday risk taking as a function of regulatory focus. Journal of Research in Personality, 45, 134-137.

Higgins, E. T. (1997). Beyond pleasure and pain. American Psychologist, 52, 1280-1300.

Higgins, E. T., Friedman, R. S., Harlow, R. E., Idson, L. C., Ayduk, O. N., \& Taylor, A. (2001). Achievement orientations from subjective histories of success: Promotion pride versus prevention pride. European Journal of Social Psychology, 31, 3-23.

Higgins, E. T., Roney, C., Crowe, E., \& Hymes, C. (1994). Ideal versus ought predilections for approach and avoidance. Distinct self-regulatory systems. Journal of Personality and Social Psychology, 66, 276-286.

Hinsz, V. B. (1981). Persuasive arguments, group polarization, and choice shifts. Unpublished master's thesis, University of Illinois, Urbana-Champaign.

Hinsz, V. B., Tindale, R. S., \& Vollrath, D. A. (1997). The emerging conceptualization of groups as information processes. Psychological Bulletin, 121, 43-64.

Hobfoll, S. E. (2001). The influence of culture, community, and the nested-self in the stress process: Advancing conservation of resources theory. Applied Psychology - An International Review, 50, 337-370.

Hofmann, D. A. (1997). An overview of the logic and rationale of hierarchical linear models. Journal of Management, 23, 723-744.

Hoever, I. J., van Knippenberg, D., van Ginkel, W. P., \& Barkema, H. G. (2012). Fostering team creativity: Perspective taking as key to unlocking diversity's potential. Journal of Applied Psychology, 97, 982-996.

Isen, A. M., Daubman, K. A., \& Nowicki, G. P. (1987). Positive affect facilitates creative problem solving. Journal of Personality and Social Psychology, 52, $1122-1131$.

James, L. R., Demaree, R. B., \& Wolf, G. (1984). Estimating within group interrater reliability with and without response bias. Journal of Applied Psychology, 69, 85-98.

Janssen, O. (2000). Job demands, perceptions of effort-reward fairness and innovative work behaviour. Journal of Occupational and Organizational Psychology, 73, 287-302.

Janssen, O. (2001). Fairness perceptions as a moderator in the curvilinear relationships between job demands, and job performance and job satisfaction. Academy of Management Journal, 44, 1039-1050.

Janssen, O. (2004). How fairness perceptions make innovative behavior more or less stressful. Journal of Organizational Behavior, 25, 201-215.

Kahn, R. L., \& Byosiere, P. (1992). Stress in organizations. In M. D. Dunnette \& L. M. Hough (Eds.). Handbook of industrial and organizational psychology (Vol. 3, pp. 571-650). Palo Alto, CA: Consulting Psychologist Press. 2 ed.

Karasek, R. A. (1979). Job demands, job decision, latitude and mental strain: Implications for job redesign. Administrative Science Quarterly, 24, 285-308.

Kark, R., \& Van Dijk, D. (2007). Motivation to lead, motivation to follow: The role of the self-regulatory focus in leadership processes. Academy of Management Review, 32, 500-528.

Kozlowski, S. W. J., \& Klein, K. J. (2000). A multilevel approach to theory and research in organizations: Contextual, temporal, and emergent processes. In K. J. Klein \& S. W. J. Kozlowski (Eds.), Multilevel theory, research, and methods in organizations: Foundations, extensions, and new directions (pp. 3-90). San Francisco, CA, US: Jossey-Bass.

Lam, T. W. H., \& Chiu, C. Y. (2002). The motivational function of regulatory focus in creativity. Journal of Creative Behavior, 36, 138-150.
Leonardelli, G. J., Lakin, J. L., \& Arkin, R. M. (2007). A regulatory focus model of selfevaluation. Journal of Experimental Social Psychology, 43, 1002-1009.

LePine, J. A., LePine, M. A., \& Jackson, C. L. (2004). Challenge and hindrance stress: Relationships with exhaustion, motivation to learn, and learning performance. Journal of Applied Psychology, 89, 883-891.

LePine, J. A., Podsakoff, N. P., \& LePine, M. A. (2005). A meta-analytic test of the challenge stressor-hindrance stressor framework: An explanation for inconsistent relationships among stressors and performance. Academy of Management Journal, 48, 764-775.

Levine, J. M., Higgins, E. T., \& Choi, H. S. (2000). Development of strategic norms in groups. Organizational Behavior and Human Decision Processes, 82, 88-101.

Liberman, N., Idson, L. C., Camacho, C. J., \& Higgins, E. T. (1999). Promotion and prevention choices between stability and change. Journal of Personality and Social Psychology, 77, 1135-1145.

Liberman, N., Molden, D. C., Idson, L. C., \& Higgins, E. T. (2001). Promotion and prevention focus on alternative hypotheses: Implications for attributional functions. Journal of Personality and Social Psychology, 80, 5-18.

Lockwood, P., Jordan, C. H., \& Kunda, Z. (2002). Motivation by positive or negative role models: Regulatory focus determines who will best inspire us. Journal of Personality and Social Psychology, 83, 854-864.

Marks, M. A., Mathieu, J. E., \& Zaccaro, S. J. (2001). A temporally based framework and taxonomy of team processes. Academy of Management Review, 26, 356-376.

Mathieu, J. E., Maynard, M. T., Taylor, S. R., Gilson, L. L., \& Ruddy, T. M. (2007). An examination of the effects of organizational district and team contexts on team processes and performance: A meso-mediational model. Journal of Organizational Behavior, 28, 891-910.

Mednick, S. A. (1962). The associative basis of the creative process. Psychologica Review, 69, 220-232.

Mischel, W. (1977). The interaction of person and situation. In D. Magnusson \& N. S Endler (Eds.), Personality as the crossroads: Current issues in interactional psychology (pp. 333-352). Hillsdale, NJ: Erlbaum.

Neubert, M. J., Kacmar, K. M., Carlson, D. S., Chonko, L. B., \& Roberts, J. A. (2008) Regulatory focus as a mediator of the influence of initiating structure and servant leadership on employee behavior. Journal of Applied Psychology, 93, $1220-1233$

Ohly, S., \& Fritz, C. (2010). Work characteristics, challenge appraisal, creativity, and proactive behavior: A multi-level study. Journal of Organizational Behavior, 31, 543-565.

Peterson, M. F., Smith, P. B., Akande, A., Ayestaran, S., Bochner, S., Callan, V., et al. (1995). Role-conflict, ambiguity, and overload: A 21-Nation study. Academy of Management Journal, 38, 429-452.

Podsakoff, N. P., LePine, J. A., \& LePine, M. A. (2007). Differential challenge stressorhindrance stressor relationships with job attitudes, turnover intentions, turnover, and withdrawal behavior: A meta-analysis. Journal of Applied Psychology, 92, 438-454.

Probst, T. M., Stewart, S. M., Gruys, M. L., \& Tierney, B. W. (2007). Productivity, counterproductivity and creativity: The ups and downs of job insecurity. Journal of Occupational and Organizational Psychology, 80, 479-497.

Raudenbush, S. W., \& Bryk, A. S. (2002). Hierarchical linear models. Thousand Oaks, CA: Sage.

Richter, A. W., Hirst, G., van Knippenberg, D., \& Baer, M. (2012). Creative self-efficacy and individual creativity in team contexts: Cross-level interactions with team informational resources. Journal of Applied Psychology, 97, 1282-1290.

Rietzschel, E. F. (2011). Collective regulatory focus predicts specific aspects of team innovation. Group Processes and Intergroup Relations, 14, 337-345.

Sassenberg, K., \& Woltin, K. A. (2008). Group-based self-regulation: The effects of regulatory focus. European Review of Social Psychology, 19, 126-164.

Schooler, J. W., \& Melcher, J. (1995). The ineffability of insight. In S. M. Smith, T. B Ward, \& R. A. Finke (Eds.), The creative cognition approach (pp. 97-133). Cambridge, MA: The MIT Press.

Semin, G. R., Higgins, T., de Montes, L. G., Estourget, Y., \& Valencia, J. F. (2005) Linguistic signatures of regulatory focus: How abstraction fits promotion more than prevention. Journal of Personality and Social Psychology, 89, 36-45.

Shin, S. J., \& Zhou, J. (2007). When is educational specialization heterogeneity related to creativity in research and development teams? Transformational leadership as a moderator. Journal of Applied Psychology, 92, 1709-1721.

Sonnentag, S., \& Frese, M. (2002). Stress in organizations. In W. C. Borman, D. R. Ilgen, \& R. J. Klimoski (Eds.). Handbook of psychology, industrial and organizational psychology (Vol. 12, pp. 453-491). New York: Wiley.

Tett, R. P., \& Burnett, D. D. (2003). A personality trait-based interactionist model of job performance. Journal of Applied Psychology, 88, 500-517.

Tierney, P., Farmer, S. M., \& Graen, G. B. (1999). An examination of leadership and employee creativity: The relevance of traits and relationships. Personnel Psychology, 52, 591-620.

Torrance, E. T. (1954). The survival of small groups under the stress conditions of survival. American Sociological Review, 19, 751-755.

Torrance, E. T. (1974). Torrance tests of creative thinking: Directions manual and scoring guide. Englewood Cliffs, NJ: Prentice Hall.

Unsworth, K. L. (2001). Unpacking creativity. Academy of Management Review, 26 289-297.

Unsworth, K. L., Wall, T. D., \& Carter, A. (2005). Creative requirement: A neglected construct in the study of employee creativity? Group and Organization Management, 30, 541-560.

Van Dyne, L., Jehn, K. A., \& Cummings, A. (2002). Differential effects of strain on two forms of work performance. Individual employee sales and creativity. Journal of Organizational Behavior, 23, 57-74. 
Vecchio, R. P. (1990). Theoretical and empirical examination of cognitive resource theory. Journal of Applied Psychology, 75, 141-147.

Wall, T. D., Bolden, R. I., Borrill, C. S., Carter, A. J., Golya, D. A., Hardy, G. E., et al. (1997). Minor psychiatric disorder in NHS Trust staff: Occupational and gender differences. British Journal of Psychiatry, 171, 519-523.

Werth, L., \& Förster, J. (2007). The effects of regulatory focus on braking speed. Journal of Applied Social Psychology, 37, 2764-2787.
Woodman, R. W., Sawyer, J. E., \& Griffin, R. W. (1993). Toward a theory of organizational creativity. Academy of Management Review, 18, 293-321.

Zhou, J. (2003). When the presence of creative coworkers is related to creativity: Role of supervisor close monitoring, developmental feedback, and creative personality. Journal of Applied Psychology, 88, 422-423. 